\title{
Annual adult health screening: barriers, challenges and effectiveness
}

\author{
Abrar A. Al Yamani'*, Fahad A. Mahnshi², Abdullah A. Alkhalifah ${ }^{3}$, Abdullah M. Alsawadi ${ }^{4}$, \\ Bader O. Alnefaie ${ }^{5}$, Hussam S. Alzahrani ${ }^{6}$, Mutasem S. Kutbi ${ }^{7}$, Amro A. Bukhari ${ }^{8}$, \\ Turki M. AlQattan', Majid T. Tounsi', Rayan A. Alharbi ${ }^{10}$
}

\author{
${ }^{1}$ Obhur Primary Health Care Center, King Abdullah Medical Complex, Jeddah, Saudi Arabia \\ ${ }^{2}$ Primary Healthcare, Medical Administration at Presidency of State Security, Riyadh, Saudi Arabia \\ ${ }^{3}$ King Abdulaziz Primary Healthcare Center, Ministry of Health, Alrass, Saudi Arabia \\ ${ }^{4}$ Multi Organ Transplant Center, Prince Sultan Military Medical City, Riyadh, Saudi Arabia \\ ${ }^{5}$ Taif Primary Healthcare Center, Ministry of Health, Taif, Saudi Arabia \\ ${ }^{6}$ Primary Health Care, Ministry of Health, Riyadh, Saudi Arabia \\ ${ }^{7}$ Transformation Management, Directorate of Health Affairs, Mecca, Saudi Arabia \\ ${ }^{8}$ Primary Health Care, Health Center in the Great Holy Mosque of Mecca, Mecca, Saudi Arabia \\ ${ }^{9}$ College of Medicine, Umm Al-Qura University, Mecca, Saudi \\ ${ }^{10}$ Primary Health Care, Ministry of Health, Mecca, Saudi Arabia
}

Received: 13 December 2021

Revised: 21 December 2021

Accepted: 22 December 2021

\section{*Correspondence:}

Dr. Abrar A. A. Yamani,

E-mail: abrar-yamani@gmail.com

Copyright: (C) the author(s), publisher and licensee Medip Academy. This is an open-access article distributed under the terms of the Creative Commons Attribution Non-Commercial License, which permits unrestricted non-commercial use, distribution, and reproduction in any medium, provided the original work is properly cited.

\begin{abstract}
Although it has been well-established that screening for early detection and intervention practices has been associated with favorable outcomes, there have been many concerns about the potential of these approaches to cause harm to the patients. In addition, evidence also shows some associated barriers and challenges to these approaches that need to be considered by healthcare authorities when planning for such approaches. The present literature review discusses annual adult health screening programs' effectiveness, barriers, and challenges. There is no doubt that these screening programs can help identify undiagnosed disorders among many patients with various conditions, like diabetes mellitus, hypertension, and different cancers. Moreover, the effectiveness of these screening programs can be best highlighted by the premarital screening program in Saudi Arabia, which targets high-risk couples for developing certain conditions and infections. However, it should be noted that there are many barriers and challenges to conducting health screening campaigns, like cultural and economic factors. Other challenges might also include the rates of false-positive tests, overdiagnosis, and knowledge about the screening programs.
\end{abstract}

Keywords: Screening, Healthcare, Prevention, Diagnosis, Early detection, Efficacy, Barriers

\section{INTRODUCTION}

Screening has been reported as an efficacious prevention modality for detecting asymptomatic patients at an early stage of the disorder to draw preferable treatment plans and enhance the outcomes. ${ }^{1}$ In addition to their favorable preventive outcomes, screening campaigns can also provide good data about the epidemiology and risk factors of some diseases within a certain population, which can also help healthcare authorities plan for mass interventions and target high-risk populations.

Although it has been well-established that screening for early detection and intervention practices has been associated with favorable outcomes, there have been many concerns about the potential of these approaches to cause 
harm to the patients. ${ }^{2,3}$ For instance, it has been demonstrated that harmful events were associated with preventive screening in screening for gestational diabetes, prostate cancer, and breast cancer. ${ }^{2,4-7}$ In addition, evidence also shows some associated barriers and challenges to these approaches that need to be considered by healthcare authorities when planning for such approaches. Thus, the present literature review will discuss the effectiveness, barriers, and challenges of annual adult health screening programs based on evidence from studies in the literature.

\section{METHODS}

This literature review is based on an extensive literature search in Medline, Cochrane, and EMBASE databases which was performed on 27 November 2021 using the medical subject headings $(\mathrm{MeSH})$ or a combination of all possible related terms, according to the database. To avoid missing potential studies, a further manual search for papers was done through Google Scholar while the reference lists of the initially included papers. Papers discussing neglected infectious diseases in the geriatrics were screened for useful information. No limitations were posed on date, language, age of participants, or publication type.

\section{DISCUSSION}

To adequately evaluate annual health screening programs, three main domains should be evaluated, including the cost, access, and feasibility of these programs. However, it should be noted that a more valid domain to assess the efficacy of the screening programs would be to assess their abilities in influencing the outcomes of the screened diseases in the communities at high risk. For instance, evidence from Saudi Arabia shows that premarital screening for thalassemia and sickle cell diseases effectively reduced the rates of risky couples from around $90 \%$ to $73 \%$ between 2005 and 2009, respectively. Accordingly, based on data from these national screening programs, it can be concluded that there is increased awareness and positive attitudes towards reducing the rates of marriage between high-risk couples that carry genetic or hereditary risk factors for developing certain conditions. Besides, relevant projections show that such positive attitudes are expected to enhance the efficacy of the screening programs and enhance the outcomes in the coming decades. Furthermore, among the factors that also contributed to the reduction in the marriage of risky couples is the presence of counseling clinics available across the Kingdom, which make these couples form a decision and increase awareness among the population. ${ }^{8-10}$

Various worldwide investigations have assessed the effectiveness of annual health screening programs for adults. These screening programs aim to identify various conditions, including breast cancer, colorectal cancer, cervical cancer, and the various approaches to identify certain diseases in newborns. However, it should be noted that antenatal screening programs are only valid among a few countries. In contrast, most countries focus on screening newborns and adults because of the high prevalence of diseases among these age groups. Furthermore, it has been shown that mass screening for serious conditions, including hypertension, diabetes mellitus, obesity, and hypercholesterolemia, is not conducted in many countries globally. In this context, we only found that Singapore is the only country that performs such mass screening events. ${ }^{11-13}$

Saudi Arabia has been the only country with a national premarital screening program for sickle cell anemia and thalassemia. We did not find any previous investigations or documented reports indicating similar campaigns for these disorders and infectious diseases in this context. This indicates that cultures can significantly influence healthcare settings and can impact the screening results against certain disorders based on the cultures of these communities. In addition, in Saudi Arabia, it has been demonstrated that mass screening for sickle cell anemia and thalassemia is mandatory for the Saudi population, which is difficult to apply in other countries. ${ }^{9,10,14}$ Moreover, it can be argued that the presence of cultural beliefs against termination of pregnancy might intervene against conducting antenatal screening programs in the country. Accordingly, it has been suggested that targeting these beliefs might sometimes be required by interference from religious, official, and tribal authorities, aiming to increase awareness between populations and enhance their attitudes towards screening programs. In this context, further research might be needed to assess the efficacy of such approaches and decide whether such campaigns should be encouraged or not. ${ }^{15,16}$

Various metabolic conditions were reported in the literature as targets of the health screening programs in adults. For instance, screening for breast cancer has been a common practice across different global communities. In addition, the published reports indicate the efficacy of the screening programs to early detect cases with breast cancer. For example, a previous retrospective investigation conducted in Saudi Arabia based on data from the first national, non-governmental screening center found that only 16 breast cancer cases were detected among 1215 screened women between 2007 and 2008. ${ }^{17,18}$ Another investigation based on screening for breast cancer using mobile mammographs showed that 47 cases with breast cancer were detected among 8061 screened women between 2009 and 2014. ${ }^{19}$ Governmental screening programs for breast cancer were also reported ${ }^{20}$. However, there has been no clear information regarding the validity of these approaches. The shortage of inadequate information regarding screening services against breast cancer might be a barrier for many people to seek these tests. For instance, it has been shown that the rate of participation in the national screening program of breast cancer was only $8 \%$ among 1135 surveyed women $\geq 50$ years old. ${ }^{11,21,22}$ 
Current trends stress the importance of screening programs to detect diabetes, hypertension, and hypercholesterolemia. This is because of the increasing burden of these diseases and related cardiovascular risk, leading to serious morbidity and mortalities among the affected populations. In addition, it has been shown that screening programs might enhance the early detection of high-risk populations and enhance compliance to treatment modalities leading to a reduced burden of these disorders and related complications. The importance of such screening programs was previously elaborated in many published investigations. For instance, it has been shown that during a national screening program of 10827 individuals, 1089, 389, and 366 cases were found to have undiagnosed hypertension, diabetes mellitus, and hypercholesterolemia, respectively. ${ }^{11}$ Therefore, these findings indicate the importance of conducting health screening programs for the early detection of these disorders and to enhance management practices. This can be adequately achieved by conducting organized routine screening campaigns. ${ }^{23,24}$ In addition, screening for colorectal cancer has also been a common practice in different healthcare settings. However, it should be noted that screening for colorectal cancer is not adequately practiced in some communities, like Saudi Arabia, despite the high prevalence of the condition among the Saudi population. In this context, a previous report from the Ministry of Health showed that early detection of colorectal cancer was established in $9 \%$ of the diagnosed cases only. ${ }^{24}$ Furthermore, it has been furtherly reported that the trends of colorectal cancer prevalence are increasing. Therefore, these findings indicate the importance of conducting national health screening campaigns for early detection and better condition management. ${ }^{25}$ In this context, a previous report by the Saudi centre for evidence-based healthcare recommended initiating a national screening program for adults at average risk of developing colorectal cancer. ${ }^{26}$ However, it should be noted that the Ministry of Health does not promote the importance of these approaches. Accordingly, it can be concluded that awareness of the importance of screening for colorectal cancer is not as high as that for breast cancer. Therefore, further efforts should be exerted to enhance this attitude. A previous study reported that among 2946 included participants, utilizing colorectal cancer screening surveys and colonoscopy rates were $5.64 \%$, and $<1 \%$ only, respectively. ${ }^{27}$

Another barrier that might also impact the effectiveness of adult annual health screening programs would be the availability of data and data encryption. For instance, targeted individuals might be concerned about the availability of their data and reduced privacy. Therefore, they might not be comfortable with participating in such campaigns. Moreover, the reduced information about screening campaigns' resources, materials, and outcomes might also impact the attitude towards participating in the screening programs. Providing information in the native language about the screening programs and related databases of the diseases of the community is also important to encourage populations to take part in such programs. For instance, in Saudi Arabia, the government only provides a list of newborn conditions in English. Therefore, based on the current recommendations and announced advantages of the screening programs in early identification and management of the different diseases, healthcare authorities should establish novel policies to encourage such campaigns and enhance awareness among the corresponding populations. Besides, it should be noted that the validity and efficacy of the healthcare screening programs were previously questioned in a long follow-up Australian investigation. This indicates that the current screening approaches should be critically reviewed in their current forms to overcome the challenges and enhance the outcomes. $^{28,29}$

Healthcare costs are another challenge that might intervene against conducting and adopting these screening programs. Logically, screening costs significantly increase secondary to conducting these approaches, representing a significant burden on healthcare settings and governments. ${ }^{28}$ However, to overcome these burdens, some recommendations can be made. One recommendation is to decrease the rates of false-positive diagnostic events and the related treatment offers. In addition, a more targeted examination can be conducted by conducting relevant tests based on the patient's gender, age, and specific risk factors. Moreover, health promotion achievements should be the main basis for health screening programs. Finally, conducting these campaigns should be flexible to meet the challenges and disease burdens based on the needs of each community. Reports also show that overdiagnosis is another challenge and barrier that might reduce the efficacy of annual health screening programs..$^{2-4,30-34}$ Reports of overdiagnosis have been reported in screening settings against different cancers and other diseases, including thyroid, prostate, thyroid cancers, attention deficit hyperactivity disorder, gestational diabetes, chronic kidney disease, ischemic heart disease, pulmonary embolism, and asthma. Heterogenous disease progression might be the reason for overdiagnosis in cancer screening. For instance, the progression of some types of cancers is rapid while others progress at a slow rate. In addition, many harms can affect patients related to overdiagnosis. For instance, these patients are usually subjected to higher rates of treatments and diagnoses secondary to overdiagnosis in a way that is not necessary to their underlying conditions. ${ }^{31,35}$ Therefore, based on these findings, it has been suggested that healthcare practitioners should aim to balance the harms and benefits of health screening programs for adults. A country-wise analysis should also be performed to decide which disorders are worth screening for in their populations and whether the available resources meet the benefits of such screening programs. For instance, it has been suggested that decision-making should be done after adequate consultation between the physician and the patient. ${ }^{36}$ Moreover, before conducting screening campaigns, it is worth noting that primary healthcare physicians should decide whether the benefits of the screening campaigns 
outweigh the harms and resources needed to perform certain screening programs as previously suggested in the recommendations by the grading of recommendations assessment, development, and evaluation system. ${ }^{32,36,37}$

\section{CONCLUSION}

There is no doubt that these screening programs can help identify undiagnosed disorders among many patients with various conditions, like diabetes mellitus, hypertension, and different cancers. Moreover, the effectiveness of these screening programs can be best highlighted by the premarital screening program in Saudi Arabia, which targets high-risk couples for developing certain conditions and infections. However, it should be noted that there are many barriers and challenges to conducting health screening campaigns, like cultural and economic factors. Other challenges might also include the rates of falsepositive tests, overdiagnosis, and knowledge about the screening programs.

\section{Funding: No funding sources \\ Conflict of interest: None declared \\ Ethical approval: Not required}

\section{REFERENCES}

1. Andermann A, Blancquaert I, Beauchamp S, Déry V. Revisiting Wilson and Jungner in the genomic age: a review of screening criteria over the past 40 years. Bull World Health Organ. 2008;86(4):317-9.

2. Moynihan R, Doust J, Henry D. Preventing overdiagnosis: how to stop harming the healthy. BMJ. 2012;344:e3502.

3. Welch HG, Schwartz L, Woloshin S. Overdiagnosed: making people sick in the pursuit of health. Beacon press. 2012.

4. Biller-Andorno N, Jüni P. Abolishing mammography screening programs? A view from the Swiss Medical Board. N Engl J Med. 2014;370(21):1965-7.

5. Rosenbaum L. Invisible risks, emotional choices-mammography and medical decision making. N Engl J Med. 2014;371(16):1549-52.

6. Metzger BE, Gabbe SG, Persson B. International association of diabetes and pregnancy study groups recommendations on the diagnosis and classification of hyperglycemia in pregnancy. Diabetes Care. 2010;33(3):676-82.

7. Bell N, Connor Gorber S, Shane A. Recommendations on screening for prostate cancer with the prostate-specific antigen test. Canad Med Assoc J. 2014;186(16):1225-34.

8. Alhamdan NA, Almazrou YY, Alswaidi FM, Choudhry AJ. Premarital screening for thalassemia and sickle cell disease in Saudi Arabia. Genetics in medicine. 2007;9(6):372-7.

9. Memish ZA, Saeedi MY. Six-year outcome of the national premarital screening and genetic counseling program for sickle cell disease and $\beta$-thalassemia in Saudi Arabia. Ann Saudi Med. 2011;31(3):229-35.
10. Alsaeed ES, Farhat GN, Assiri AM. Distribution of hemoglobinopathy disorders in Saudi Arabia based on data from the premarital screening and genetic counseling program, 2011-2015. J Epidemiol Glob Health. 2018;7(1):41-7.

11. Gosadi IM. National screening programs in Saudi Arabia: Overview, outcomes, and effectiveness. J Infect Public Health. 2019;12(5):608-14.

12. Alonazi WB. Exploring shared risks through publicprivate partnerships in public health programs: a mixed method. BMC Public Health. 2017;17(1):571.

13. Cheema S, Maisonneuve P, Lowenfels AB, Abraham A, Doraiswamy S, Mamtani R. Influence of Age on 2040 Cancer Burden in the Older Population of the Gulf Cooperation Council (GCC) Countries: Public Health Implications. Cancer Control. 2021;28:10732748211027158.

14. Thieu H, Bach Dat B, Nam NH. Antibiotic resistance of Helicobacter pylori infection in a children's hospital in Vietnam: prevalence and associated factors. Minerva Medica. 2020;111(5):498-501.

15. Alswaidi FM, O'Brien SJ. Is there a need to include HIV, HBV and HCV viruses in the Saudi premarital screening program on the basis of their prevalence and transmission risk factors? J Epidemiol Comm Health. 2010;64(11):989-97.

16. Abdullah SM. Prevalence of Hepatitis B and C virus infection and their co-relation with hematological and hepatic parameters in subjects undergoing Premarital Screening in the Jazan Region, Kingdom of Saudi Arabia. Pak J Med Sci. 2018;34(2):316-21.

17. Abulkhair OA, Al Tahan FM, Young SE, Musaad SM, Jazieh AR. The first national public breast cancer screening program in Saudi Arabia. Ann Saudi Med. 2010;30(5):350-7.

18. Dibas M, Doheim MF, Ghozy S, Ros MH, El-Helw GO, Reda A. Incidence and survival rates and trends of skull Base chondrosarcoma: A Population-Based study. Clin Neurol Neurosurg. 2020;198:106153.

19. Al Mulhim FA, Syed A, Bagatadah WA, Al Muhanna AF. Breast cancer screening programme: experience from Eastern province, Saudi Arabia. Eastern Mediterranean Health J. 2015;21(2):111-9.

20. Akhtar SS, Nadrah HM, Al-Habdan MA, et al. First organized screening mammography programme in Saudi Arabia: preliminary analysis of pilot round. Eastern Mediterranean Health J. 2010;16(10):1025-31.

21. El Bcheraoui C, Basulaiman M, Wilson S, Daoud F, Tuffaha M, AlMazroa MA, Memish ZA, Al Saeedi M, Mokdad AH. Breast cancer screening in Saudi Arabia: free but almost no takers. PLoS One. 2015 16;10(3):e0119051.

22. Son PT, Reda A, Viet DC, Quynh NXT, Hung DT, Tung TH, Huy NT. Exchange transfusion in the management of critical pertussis in young infants: a case series. Vox Sang. 2021;116(9):976-82.

23. Al-Daghri NM, Al-Attas OS, Alokail MS, Alkharfy KM, Yousef M, Sabico SL, Chrousos GP. Diabetes mellitus type 2 and other chronic non-communicable 
diseases in the central region, Saudi Arabia (Riyadh cohort 2): a decade of an epidemic. BMC Med. 2011;9:76.

24. Alyabsi M, Alhumaid A, Allah-Bakhsh H, Alkelya M, Aziz MA. Colorectal cancer in Saudi Arabia as the proof-of-principle model for implementing strategies of predictive, preventive, and personalized medicine in healthcare. EPMA J. 2020;11(1):119-31.

25. Mosli MH, Al-Ahwal MS. Colorectal cancer in the Kingdom of Saudi Arabia: need for screening. Asian Pacific J Cancer Prev. 2012;13(8):3809-13.

26. Alsanea N, Almadi MA, Abduljabbar AS, Alhomoud S, Alshaban TA, Alsuhaibani A, et al. National Guidelines for Colorectal Cancer Screening in Saudi Arabia with strength of recommendations and quality of evidence. Ann Saudi Med. 2015;35(3):189-95.

27. Khoja A, Aljawadi M, Al-Shammari SA, Bokhari NN, Aldarwish AA, Mardini WK, Khoja TA. Utilization of Colorectal Cancer Screening among Saudi Elderly Population: A Study from the Saudi National Survey for Elderly Health. Asian Pac J Cancer Prev. 2018;19(12):3401-7.

28. Hackl F, Halla M, Hummer M, Pruckner G. The Effectiveness of Health Screening. Health Economics. 2014;24.

29. El-Qushayri AE, Dahy A, Reda A, Mahmoud MA, Mageed SA, Kamel AMA, Ghozy S. A closer look at the high burden of psychiatric disorders among healthcare workers in Egypt during the COVID-19 pandemic. Epidemiol Health. 2021;43:e2021045.

30. McCaffery KJ, Jansen J, Scherer LD. Walking the tightrope: communicating overdiagnosis in modern healthcare. BMJ. 2016;352:348.

31. Welch HG, Black WC. Overdiagnosis in cancer. J Nat Cancer Institute. 2010;102(9):605-13.
32. Bell N, Connor Gorber S, Tonelli M. From ABCs to GRADE: Canadian Task Force on Preventive Health Care's new rating system for clinical practice guidelines. Canadian family physician Medecin de famille canadien. 2013;59(12):1282-9.

33. Carter JL, Coletti RJ, Harris RP. Quantifying and monitoring overdiagnosis in cancer screening: a systematic review of methods. BMJ. 2015;350:7773.

34. Barratt A. Overdiagnosis in mammography screening: a 45 year journey from shadowy idea to acknowledged reality. BMJ. 2015;350:867.

35. El-Qushayri AE, Ghozy S, Reda A, Kamel AMA, Abbas AS, Dmytriw AA. The impact of Parkinson's disease on manifestations and outcomes of Covid-19 patients: A systematic review and meta-analysis. Rev Med Virol. 2021;2278.

36. Bell NR, Grad R, Dickinson JA, Singh H, Moore AE, Kasperavicius D, Kretschmer KL. Better decision making in preventive health screening: Balancing benefits and harms. Can Fam Physician. 2017;63(7):521-4.

37. Guyatt GH, Oxman AD, Vist GE, Kunz R, FalckYtter Y, Alonso-Coello P, Schünemann HJ; GRADE Working Group. GRADE: an emerging consensus on rating quality of evidence and strength of recommendations. BMJ. 2008;336(7650):924-6.

Cite this article as: Yamani AAA, Mahnshi FA, Alkhalifah AA, Alsawadi AM, Alnefaie BO, Alzahrani HS, et al. Annual adult health screening: barriers, challenges and effectiveness. Int $\mathbf{J}$ Community Med Public Health 2022;9:518-22. 